\title{
A LEAN APPROACH TO OPTIMIZE BIM INFORMATION FLOW USING VALUE STREAM MAPPING
}

SUBMITTED: December 2017

REVISED: October 2018

PUBLISHED: November 2019 at https://www.itcon.org/2019/25

EDITOR: Turk Ž.

DOI: $10.36680 /$ j.itcon.2019.025

Martin Michaud, Ph.D. candidate,

Department of Construction Engineering, École de Technologie Supérieure; martin.michaud.2@ens.etsmtl.ca

Eva-Charlotte Forgues, M. Ing.,

Department of Construction Engineering, École de Technologie Supérieure; eva-charlotte.forgues.1@ens.etsmtl.ca

Vincent Carignan, M. Ing.,

Department of Construction Engineering, École de Technologie Supérieure; Vincent.carignan.1@ens.etsmtl.ca

Daniel Forgues, Ph.D.,

Department of Construction Engineering, École de Technologie Supérieure;

Daniel.forgues@etsmtl.ca

Claudiane Ouellet-Plamondon, Ph.D.,

Department of Construction Engineering, École de Technologie Supérieure;

Claudiane.ouellet-plamondon@etsmtl.ca

SUMMARY: Building Information Modelling (BIM) was introduced in the Architecture, Engineering and Construction (AEC) industry as a shared information platform that aims to improve productivity through better collaboration. The assumption is that a virtual integration of information among project stakeholders would reduce the issues around the fragmented nature of the processes that still prevail in the construction field. This paper aims to highlight the sources of waste in the information flows between an architecture firm, a Mechanical, Electrical and Plumbing (MEP) engineering firm, a general contractor (GC) and a MEP subcontractor (SC) in a BIM project - an aspect of waste little covered in the Lean literature. The focus is on the MEP process from early design to the final product. This research contributes to the identification of the main barriers to information flow, including the conflicts and waste sources that emerge from using BIM, as well as to the identification of emerging successes. Moreover, the findings offer practical implications by providing a visual of the patterns emerging from the use of BIM. Finally, by providing potential waste reduction strategies such as Value Stream Mapping (VSM) this work allows construction actors to identify and reduce sources of waste in their processes.

KEYWORDS: BIM, collaboration, auto-confrontation, information flows, waste

REFERENCE: Martin Michaud, Eva-Charlotte Forgues, Vincent Carignan, Daniel Forgues, Claudiane OuelletPlamondon (2019). A lean approach to optimize BIM information flow using value stream mapping. Journal of Information Technology in Construction (ITcon), Vol. 24, pg. 472-488, DOI: 10.36680/j.itcon.2019.025

COPYRIGHT: () 2019 The author(s). This is an open access article distributed under the terms of the Creative Commons Attribution 4.0 International (https://creativecommons.org/licenses/by/4.0/), which permits unrestricted use, distribution, and reproduction in any medium, provided the original work is properly cited. 


\section{INTRODUCTION}

The traditional vision of construction management focuses on the division of a project into lots and activities, while BIM projects focus on an information-centric management. Winch (2009) explained that the goal of construction management is to ensure that the process of producing the information describing the deliverables corresponds to what is expected by the client. The problem is the information gaps between the different phases of a project. Indeed, the product is not even defined at the beginning of a project. BIM presents a viable solution to this problem, as it aims to facilitate the exchange of building information by implementing a centralized platform designed to ease information sharing. However, the inherent difficulty in transferring information properly and accurately between the actors throughout the phases of a project limits the advantages of BIM (Coates et al. 2010). The BIM benefits expected in a project are an improved coordination and collaboration, an optimization of scheduling and costs, reduced drafting time with no loss of quality or any increased cost, improved conflict detection and risk mitigation, a high level of customization and flexibility and streamlined building life cycle management. BIM implementation requires an adaptation of the involved parties due to process changes (Volk, Stengel, and Schultmann 2014). Indeed, a successful deployment of BIM requires a review of the way things are done with a transition from a document-centric approach (traditional) to an information-centric approach. BIM can be seen as the reengineering concept founded and developed by Hammer and Champy (1993) and defined as: "the fundamental rethink and radical redesign of business processes to generate dramatic improvements in critical performance measures - such as cost, quality, service and speed.” This concept promotes a process-centred organization to provide significant gains in performance.

The value of BIM is often described as providing processes and tools to streamline the production and exchange of information through a unique and shared platform (Eastman et al. 2011); enabling all stakeholders to share the same set of data, thereby avoiding all the issues of information loss, alterations or overproduction (Crotty 2013). $\mathrm{BIM}$ is used as a platform for data management either for the architect, the owner or any other actor in the process to retrieve or display information in a consistent format (Goedert and Meadati 2008). Information processing plays a major role in construction projects as it includes all the communication, exchange, collection, processing and distribution of information (Zhang, Liu, and Chan 2018). Several issues have been identified, such as the lack of trust and coordination between the actors of the supply chain, problems with integration in the supply chain, and the difficulties inherent in breaking traditional work patterns. There is currently a lack of research on this subject in the literature.

This paper explores the information processing issues in a BIM project between firms, with a focus on the Mechanical, Electrical and Plumbing (MEP) process of a Private-Public Partnership (PPP) project. The highest stakes regarding the information process are observed within the MEP process, as it is the last process in the design chain and it provides information concerning a building's operation and maintenance. During a PPP project, the collaboration between professionals and SCs is eased because all stakeholders are engaged early in the project with only one contract linking all the team members. The aim of the research is to identify conflicting and successful areas in the BIM using an empirical approach through the collaborative mapping of stakeholder's individual perceptions. Process maps were produced and compared to highlight what must be improved regarding BIM information processing. This paper offers an observatory study designed to provide significant insight into the current situation in the construction industry. A diagnosis of the current problems is provided in order to find solutions. The main novelty of the paper is its approach that allows the visualization of the information flows in BIM construction projects. This visualization approach provides a tool to better understand the processes and helps to identify the sources of waste within information flows.

After this introduction, this article contains five more sections. A literature review focusing on BIM and its impact on construction processes is followed by a description of the methodology used for the research and a description of the case study. The subsequent section gives an analysis of the results gathered from the case study. A discussion section then provides potential solutions to the problems identified during the study. Finally, the last section summarizes the paper's contributions and limitations and presents the conclusions along with some recommendations for future work. 


\section{THE BIM APPROACH AND THE NOTION OF FLOW}

\subsection{BIM and its impact on construction processes}

Four major elements defining the BIM rhetoric have been identified (Miettinen and Paavola 2014): (1) the use of BIM models to regroup all relevant data; (2) a new integrated way of working driven by the need for better collaboration around a shared platform and interoperability between systems; (3) the use of BIM throughout the entire lifecycle of a building; and (4) an increase in productivity and efficiency. However, these elements are part of an idealistic BIM view, as several constraints act as barriers to a proper BIM implementation, i.e. the fragmented nature of the construction industry, particularly in the field, rivalry between partners in a project or the presence of disruptions in construction projects. Each of the four elements mentioned by Miettinen and Paavola (2014) can be integrated into the study of construction processes. This section offers a comprehensive literature analysis in an attempt to determine the elements that are preventing BIM from being implemented in the construction field.

Firstly, transferring models into a centralized platform will facilitate information sharing. Having a centralized platform containing all the information of the different stakeholders helps to highlight the incompatibilities between the systems and to facilitate coordination while providing a common 3D vision of the project to all the stakeholders (Deutsch 2011). The full potential of BIM benefits can only be realized if a common platform is shared among all stakeholders, including the supply chain (Taylor and Bernstein 2009).

Secondly, a new collaborative way of working will allow to maximize BIM benefits. The traditional way of producing and exchanging information is through documents that are "pushed" as deliverables from phase to phase to the next actors in the process (Kiviniemi 2011). In contrast, BIM's information-centric approach supports the processes of a project by providing pre- and post-conditions to each activity to limit waste and allow more informed decisions. In a non-lean organization, the work is pushed through the system, whereas in a lean system, actors pull the work, making the system react to the client's demands. For example, in a traditional push system, the architect produces a model and transmits it to the engineer, who creates the next model according to the information provided by the architect. This process goes on until it reaches the sub-contractor responsible for the construction. In a pull system, the architect asks the engineer for the information required to produce an accurate model. This process is repeated with each actor of the process to limit sources of waste, such as rework due to lack of information or overproduction of information.

Thirdly, the use of BIM throughout the entire lifecycle of a building forces the early phases to be planned so as to limit problems during the construction and operation and maintenance phases. With the implementation of BIM and the acknowledgement of the importance of information flows in the construction industry, these processes are now studied to identify sources of waste, such as overproduction of information or problems in information transfer. However, an important aspect rarely considered in the construction industry regarding the reduction of waste is to tackle it from the source. Indeed, up to $33 \%$ of waste originates from design (Innes 2004). Thus, the identification and reduction of sources of waste must be done during the design phase of a construction project. Early actions will help reduce the amount of waste throughout a construction project (Osmani, Price, and Glass 2005). However, these studies focus only on materials and/or work flows and do not consider information flows as a potential source of waste.

Fourthly, greater efficiency and higher productivity can be achieved by the standardization and proper management of information flows. Turk (2000) investigated the concept of flow in detail. He proposed a model integrating the workflow, the material flow and the information flow that clearly shows how these flows are interrelated. The main problem resulting from not managing these interactions is that when there is a problem in one flow, it affects the other flows' waste. For example, the production of incorrect information will impact the material flow, as it will cause the wrong equipment or material to be ordered, leading the workflow to lose time waiting for the correct equipment/material to be ordered and delivered.

This review has identified four distinct ways in which BIM can impact construction projects: (1) by replacing traditional construction processes with the transfer of models into a centralized platform; (2) by employing a new collaborative way of working; (3) by incorporating lifecycle management into the construction supply chain; and (4) by the standardization and proper management of information flows. These four elements show the importance of information flows in the implementation of BIM.

The concept of flow is an inherent part of lean thinking. One concept of lean manufacturing is that production is viewed as a flow that describes how information and material are being processed (Koskela 2000). Any discrepancy in the flow creates problems, also called wastes, which can impact the information, work or material 
flows. To improve these flows in construction projects, the sources of waste must be identified. To date, waste within information flows in construction remains a subject that is not well-documented.

\subsection{The notion of flow and the importance of information flow}

Garcia Lopez (2017) describes information flows as support flows and explains their importance in construction. As a part of developing the Transformation-Flow-Value generation (TFV) theory, (Koskela 2000) states that the most important principle is to reduce variability; in other words, to increase standardization. Over the past several years, a number of studies have been conducted to increase standardization in construction (Martinez et al. 2015; Aapaoja and Haapasalo 2014; Yu et al. 2009).

Many models have been developed to manage information flows with the goal of reducing waste. Otjacques, Post, and Feltz (2003) proposed a proof-of-concept tool designed to help manage information flows during construction projects by mixing push and pull functionalities. Their tool provides solutions to information management problems such as information overload, retrieval or asymmetry, all of which are sources of waste within information flows. However, the research scope is limited to the construction phase, with no accounting of the waste generated by flaws in the design process.

Tribelsky and Sacks (2010) measured information flows in the design process through data collected from several construction projects. The data they gathered was transacted through a web server which allowed their research to access quantifiable data. They identified seven numerical indices (action rate, package size, work in process, batch size, development velocity, bottlenecks and rework) with which to measure information flows and to detect the presence of waste. However, while this research allowed quantitative data on sources of waste to be collected, it did not address the need to collect qualitative data, such as data on issues of coordination, information transfer or on the over-production of information due to misunderstandings about the process.

To facilitate information management, the quality and reliability of the information created must be quite high. Zadeh, Staub-French, and Pottinger (2015) reviewed four types of information quality issues: information incompleteness, value inaccuracy, spatial inaccuracy and model incompatibility. Garcia Lopez and Fischer (2016) studied flows such as information flows between activities during the construction phase. They collected data to help managers cope with workflow variability in the field. While variability has been identified as a source of problems in construction, no other source of waste was identified during this research.

These problems observed in BIM construction projects are responsible for several sources of waste in the information management process, including rework due to inaccurate or incomplete information or overproduction of information due to the generation of unnecessary information. Standardization must be in the foundation of an improved information flow. Mirarchi et al. (2017) recently proposed a method to improve the information flow in construction by increasing standardization using automated IFC-based processes. Their aim was to improve interoperability within BIM environments. While their results offer positive outcomes, their paper's focus was limited to the sharing and exchange of information. In contrast, the approach used in this article aims to identify additional sources of problems and to propose potential solutions for each.

Compared to the Architecture, Engineering and Construction (AEC) industry, research on information flows in other industries is much more advanced and can provide important insights on how to improve information flows in construction projects. Cetin and List (2002) proposed a new approach for integrating the information flow and the physical flow in transportation networks. Their approach focuses on the interaction between flows; to provide a better transportation system, both flows should be expressed in the same model to determine the impact of waste in the information flow. Attempts to reduce waste in workflows and in material flows without including the information flows cannot give optimal results due to the interrelation between these flows. As another example, Wang et al. (2010) have devised a method that allows the management and control of information processing in the supply chain process in the military industry.

BIM has been introduced in the construction industry to improve interoperability and collaboration among the parties involved in construction projects (Eadie et al. 2014). However, several issues can be observed with BIM collaboration, such as the quality and quantity of information exchanged between the involved parties, the resistance to change, the lack of understanding of the entire information flows process and the lack of common shared vision (Forgues et al. 2016). These issues tend to keep the actors from the same project or even the same process apart, thus facilitating the creation of waste within the information flows. However, recent research has shown that there is a desire to reduce waste in construction processes with the help of BIM. Ahankoob et al. (2012) studied the potential impact that BIM can have on reducing waste in the design phase by focusing on the materials 
flow, and Porwal (2013) focused on addressing the methods of waste management at the source while using BIM. Both studies show the potential of BIM in construction and its role in the identification and reduction of waste in BIM processes. However, as seen earlier, while BIM was developed to improve collaboration and information flows, none of these studies have addressed waste in information processing.

Many underlying factors can affect the results from one project to another. For example, the contract type (Moore and Dainty 2001), or the quality of the project participants as well as their BIM maturity (Kassem and Succar 2017). The contract defining the project delivery impacts the team integration and group cohesion (Franz et al. 2016). For example, with a design-build delivery, all actors join the project during the design phase, changing their relationships. With a traditional delivery, subcontractors are brought into a project much later, leading to a lower level of communication and coordination. Franz et al. identified five classes of project delivery methods and observed that high cohesion and team integration led to positive effects, such as lower costs or higher client ratings for building system quality. However, they did not consider the maturity level of the actors participating in a project. In a BIM project, players do not have the same experience with BIM, impacting the results on the project. As more and more actors are using BIM in their projects, their BIM integration maturity is developing; this ongoing process will solve some problems such as the organization of work issues or semantic gap (Smits, van Buiten, and Hartmann 2017).

This review has identified several studies focused on information flows, but much work remains to bring the construction field up to the level of other industries. Of particular interest is the need to manage flow and add value through better information processing. This paper provides a way to fill the gap identified in this review: the lack of knowledge during the design phase of construction projects, specifically the lack of qualitative data on sources of waste in information flows.

\section{METHODOLOGY}

This paper presents the results, obtained via an investigation, of a case study of a $\$ 265.7 \mathrm{M}(\mathrm{CAD})$ jail replacement construction project, a public private partnership (PPP). Due to the increased complexity created by the duplication of all the technical systems required by the security requirements, the general contractor (GC) decided to invite subcontractors (SC) to participate from the design phase to the end of the project, and to use BIM to help reduce design errors and ease collaboration and communication throughout the entire project. Considering these factors, this exploratory research provides data for a PPP project using a design-build delivery with stakeholders that have a range of maturity levels in the use of BIM. The mechanical, electrical and plumbing (MEP) process is the most complex process to coordinate (Wang and Leiti 2016). The research therefore focused on the MEP process coordination.

This study used an investigative method based upon a case study research approach (Yin 1994; Hancock and Algozzine 2016; Fellows and Liu 2015). The data was collected from October 2015 to February 2016 through two interviews (each one and a half hour long) with each participant. The auto-confrontation technique was used during the interviews and was part of the data collection process (Forgues et al. 2016). These interviews occurred at the end of the construction project when the processes were over, and the participants could easily remember what had been done during the various phases of the project. The participants were the project managers of the architecture firm and of the MEP engineering firm, the MEP contractor and the MEP BIM coordinator from the GC. At the end of the construction project, the research protocol was specifically designed to help the participants map the information flow between the parties involved in the MEP process. To obtain accurate and consistent results among the participants, the mapping has been adapted based on the standard graphic of the Business Process Model and Notation (BPMN). BPMN allows actors to create a graphical representation for specific processes in a process model by using a small number of elements in simple diagrams (Scherer and Ismail 2011) (see table 1). The five main elements are easy to manipulate for process modelling by an unexperienced participant. BPMN's five main elements were used to simplify the mapping and to gather the necessary information about the communication workflow between the various stakeholders, as listed in Table 1.

The data gathering for the process modelling focuses on three important aspects:

- The workflow between the different actors;

- The input and output of information for each activity; and

- The representation of this information in material objects or documents.

To study interoperability and the number of models in the flows, a new aspect was proposed to support the process:

- A technological tool: The format and software used to transfer the documents and information. 
Table 1. Elements present in the BPMN mapping

\begin{tabular}{l|l} 
Element & BPMN - Icon \\
\hline Beginning & \\
\hline End & \\
\hline Activity & \\
\hline Document/Information & \\
\hline Decision &
\end{tabular}

The auto-confrontation technique used here is a method developed in cognitive science to confront the participant with their own reality (Clot et al. 2000). This technique was used by Forgues et al. (2016) to demonstrate maturity issues with BIM. In that study, the participants and the researchers co-constructed maps between the lifecycle of a construction project and the stakeholders (Forgues et al. 2016). The mapping allows the research collaborators to obtain data highlighting the different points of view of the various actors of a single process, thus pinpointing the issues and reasons for the presence of barriers between the stakeholders and the sources of hindrances to collaboration.

The method was adapted for the identification of the sources of waste by reusing the data collected in this empirical validation. The flows were revised to isolate the good and bad practices that are often mentioned in the literature, as well as to validate the existing theories and observations on issues in these practices. After using the autoconfrontation technique to complete their maps, the participants were asked to individually highlight areas of conflict in the process flows. The efficiencies and inefficiencies in the flows could be identified by studying these areas of conflict and their location in the maps. Next, the analysis phase, the process maps created in the first phase were refined to fit the BPMN model and to allow the participants to comment on the results. By analyzing the maps, the research team isolated the different perceptions, the semantic differences and other barriers, as well as the contradictions between the perceptions and finally, the ambiguity throughout the entire process to highlight the sources of waste in information processing.

\section{RESULTS}

The results are divided into two sections. The first section presents the information processing issues that were diagnosed from the comparison of the process maps produced by the various specialties. The second section presents the good practices in the processes as a suggestion to improve information processing through standardization.

\subsection{Information processing concerns}

Four categories of problems were identified by comparing the maps realized with the stakeholders: 1) the coordination of the work between stakeholders; 2) the variety of software used by the stakeholders; 3) the difficulties in breaking traditional work patterns; and 4) issues in the supply chain integration, as having stakeholders not included in the BIM process led to coordination problems.

\subsubsection{Coordination of the work between stakeholders}

Through the analysis of the flows, two main issues were observed: the gap between traditional and BIM processes and the overproduction of information. The MEP contractor realized the map shown in Figure 1 that shows his understanding of the electromechanical coordination process between the MEP contractor, the GC and the engineer with a focus on the coordination of the electromechanical model between these three stakeholders. 


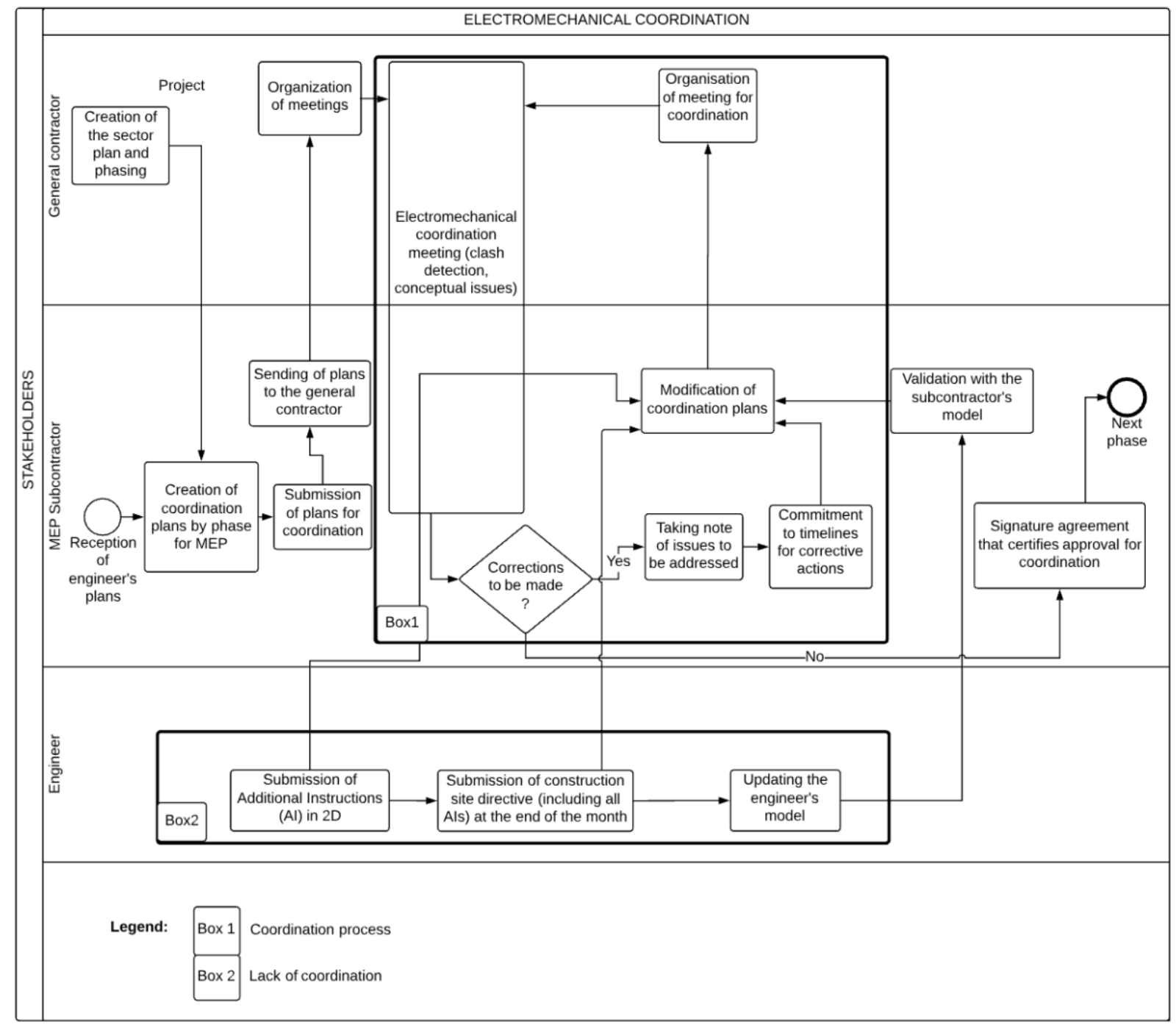

Figure 1. Coordination process realized by the MEP contractor

As illustrated in Figure 1, the MEP contractor is responsible for the creation of the coordination plans by phase for the MEP according to the GC's and the engineer's needs. Once the coordination plans are generated, monthly meetings for coordination are organized for the ongoing validation of the plans. The MEP contractor mapped a process with a good coordination (Box 1) and a process with a lack of coordination (Box 2).

Box 1 frames a set of activities that illustrates the coordination process between the GC and the MEP SC. According to the MEP SC, this part of the process was tedious at first due to the implementation by the GC of a new coordination process between these stakeholders. A lack of understanding and resistance to change occurred when moving from traditional to BIM processes. However, at the end of the project, when everyone became accustomed to the new process, it went faster.

Box 2 shows the transmission of additional instructions and construction directives between the MEP SC and the engineer. During this phase, the engineer was not included in the coordination process (Box 1) with the two other stakeholders. Because of this lack of coordination, the engineer could not be aware of the stakeholders' information needs, which led to an over-production of information from the engineer and errors in the engineer's documents. "There was no communication between the plumbing coordinator and the plumbing installation team because the installers are used to doing a job from point A to point B by the shortest way possible. They did not change their practice and it affected others. Moreover, the electricity installation team was absented from all meetings when it would have been relevant because it resulted in a lot of rework at the end which could have been avoided." This statement from the GC shows the resistance to change from traditional to BIM practices from two project 
stakeholders. This lack of coordination led to the creation of waste, such as rework and loss of time leading to the overproduction of information. It also demonstrates that while each specialty may have an excellent knowledge and comprehension of their own work, without BIM, participants cannot have a vision of the overall process and the work of the other specialties. Dossick and Neff (2011) qualifies this as seeing the processes with specialty lenses; these participants were focused exclusively on their own process(es). They ignored the interrelation between their work and that of other actors, especially how their work was affecting the work of the others. This lack of communication and coordination between stakeholders tends to produce information based on their traditional process and their own knowledge. Thus, the information provided does not meet all the recipient's needs (it may include unnecessary information and/or lack some required information), leading to requests for information from the recipient and an overproduction of information.

\subsubsection{Variety of software among stakeholders}

The interoperability between the various software used and the number of models produced by each discipline were major problems during the project. The different stakeholders used numerous platforms, including CAD 3D, Revit, Tekla, etc. (Table 2). Coordination problems were related to interoperability issues between these software products. For example, there were conflicts between the MEP SC's and the engineer's models because they each used and updated their own models in parallel, which created problems with the model coordination. There were also information processing issues in dealing with both 2D and 3D CAD and BIM models: "Since the MEP SC only got $2 D$ drawings from the engineer, they had to integrate the information in our own model." This statement from the GC showed an interoperability gap between stakeholders leading to a loss of time for the MEP SC with the remodelling, understanding and coordinating of the changes, considerably slowing the overall process.

Table 2. Models and authoring software by specialties

\begin{tabular}{|l|l|l|}
\hline Stakeholders & $\begin{array}{l}\text { Number of Models according } \\
\text { to specialty }\end{array}$ & Software \\
\hline Professionals & $\begin{array}{l}\text { Architecture: 6 Models } \\
\text { Mechanical engineering: 3 } \\
\text { Models } \\
\text { Electrical engineering: 1 Model } \\
\text { Structural engineering: 1 Model }\end{array}$ & $\begin{array}{l}\text { Revit } \\
\text { Revit } \\
\text { Revit } \\
\text { Revit \& Tekla }\end{array}$ \\
\hline $\begin{array}{l}\text { Subcontractors } \\
\text { (SCs) }\end{array}$ & $\begin{array}{l}\text { Ventilation: 1 Model + 15 Plans } \\
\text { Plumbing/Heating: 2 Models }\end{array}$ & $\begin{array}{l}\text { Revit \& AutoCAD 3D } \\
\text { Revit } \\
\text { Fevit \& AutoCAD 2D } \\
\text { Plans protection: 1 Model + 2 } \\
\text { Electricity: 1 Model } \\
\text { Structure: 3 Models }\end{array}$ \\
\hline
\end{tabular}

\subsubsection{Difficulties in breaking traditional work patterns}

In a traditional construction project, the parties involved usually work in silos. The inherent lack of coordination and communication limits the knowledge and understanding of the other actors' processes. During this research, the actors revealed some of the difficulties involved in breaking traditional work patterns. Figure 2 shows how the architect perceived the information flow during the final design phase.

The task of the architect during this mapping exercise was to represent his own final design process and that of the engineers with a focus on the information flow and the coordination between them. While the architect's activities and flow are well detailed, the engineering part is almost a black box, with coordination meetings and the production of drawings as the only information exchange link. Figure 3 shows how the MEP SC perceived the information flow during the execution phase.

With the same task as the architect, the MEP SC was asked to map his execution process and those of the other stakeholders. Figure 3 shows that the MEP SC was not able to separate the sources of information inputs from different professionals; he decided to group them as one stakeholder. Furthermore, it appears that, he perceived the production and exchange of information with professionals as being limited to only one activity during the whole process. 


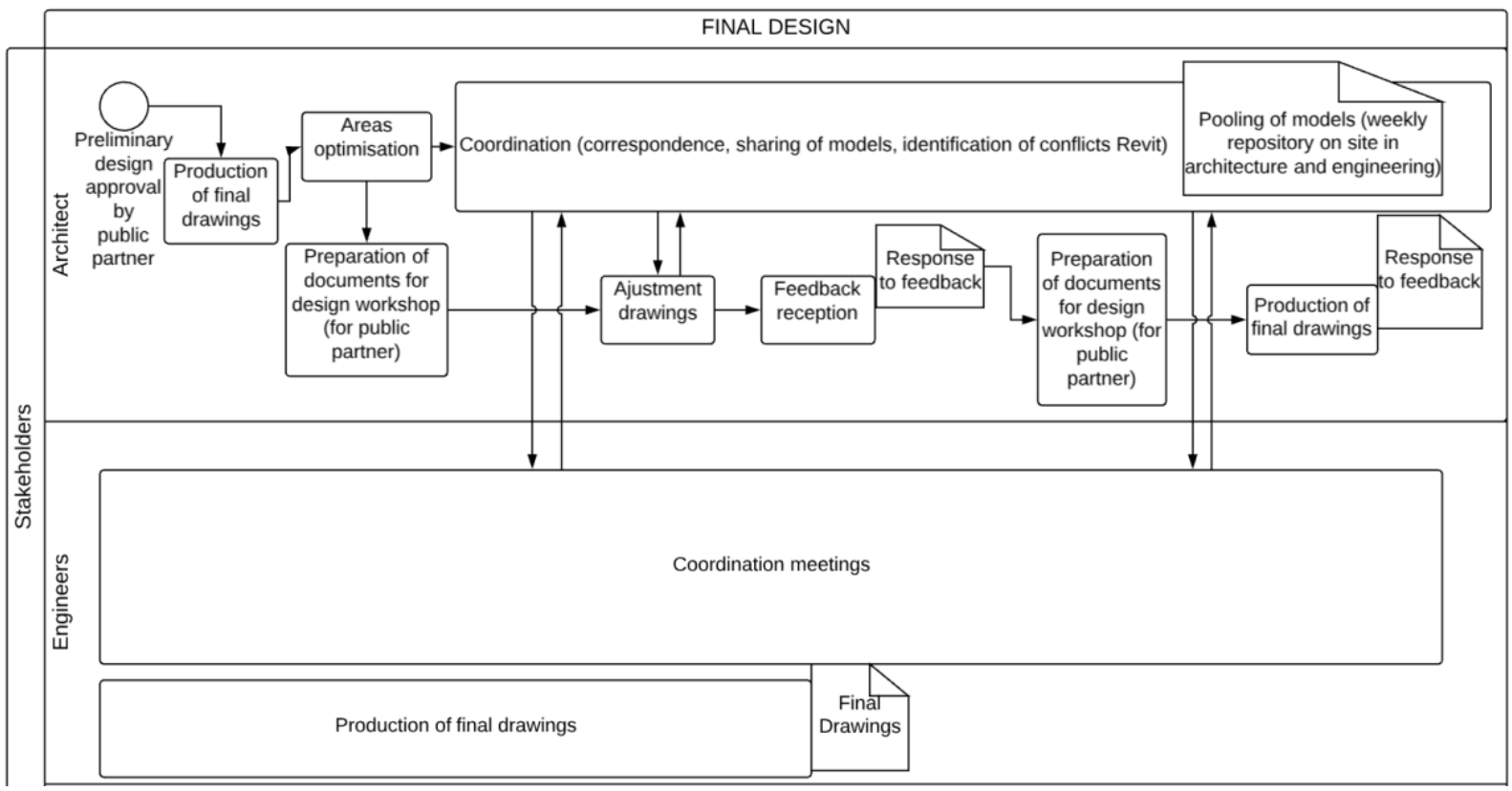

Figure 2. Examples of problems with mapping the processes of other actors from an architect's perspective

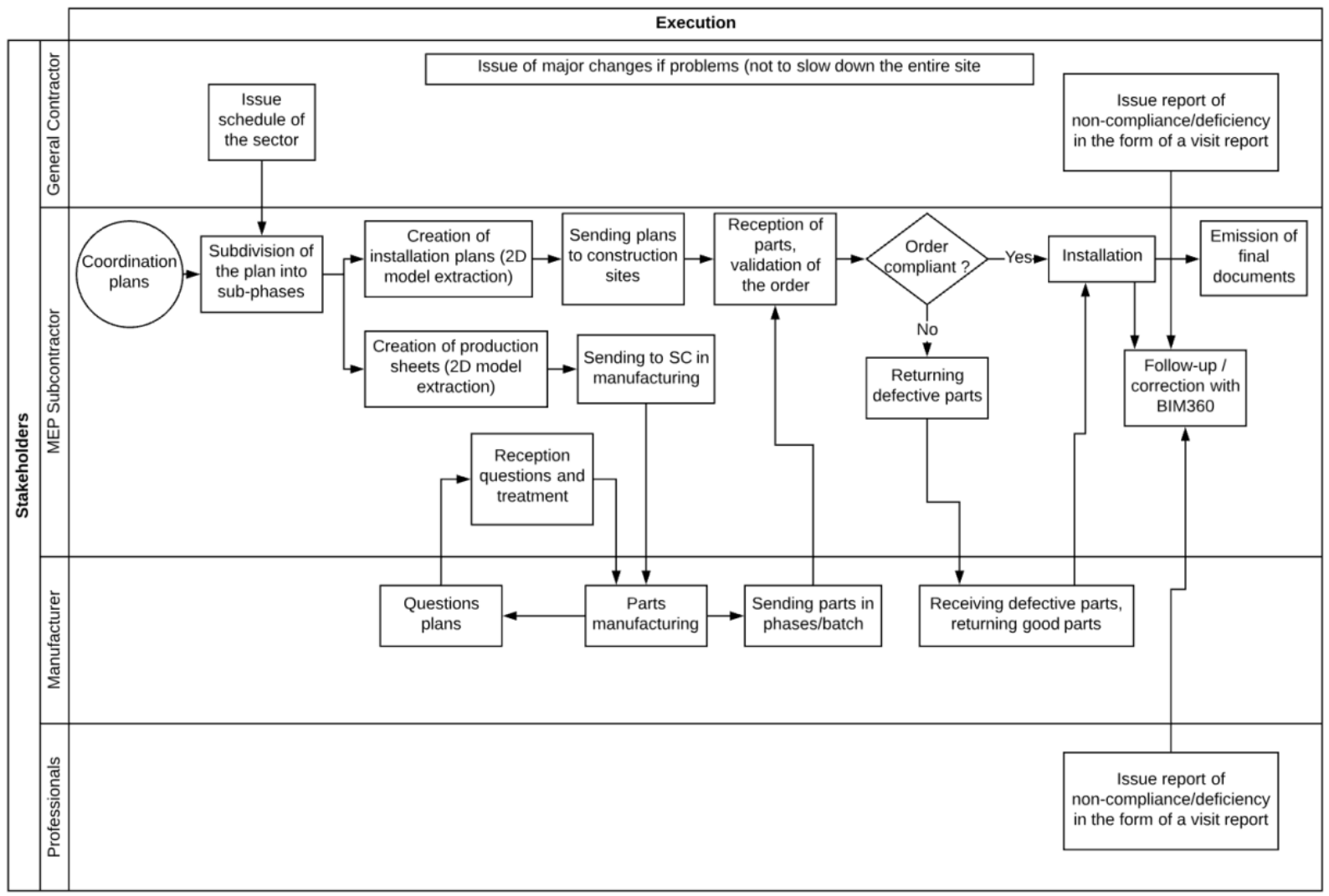

Figure 3. Examples of problems with mapping the processes of other actors from a MEP SC's perspective

Analysis of these mappings and interviews indicates a limited understanding of the information needs between the various stakeholders. This could be explained by the traditional Push approach to the production and exchange of information. Even if there is a shift from a fragmented to an integrated information platform, the practices deeply imbedded in specialists' mental models remain. The traditional pattern of producing and exchanging information is repeated. The prescriptive approach in which design information is "pushed" using static contractual documents (drawings and specs) in a linear design and construction cycle conflicts with the need to understand the information 
required for each use of BIM in subsequent processes (the Pull approach). Without the knowledge of each other's needs, the actors create the information they need for their deliverables with no concern for the inputs required by the other specialities, creating an overproduction of information. This situation leads to the main source of waste in information processing.

\subsubsection{Supply chain integration}

A major problem in construction supply chain management is the lack of consideration for the role that manufacturers can play in the overall information processing strategy. In this case, they either did not participate in coordination meetings or did not use BIM technologies. As Taylor and Bernstein (2009) argue, the integration of all the stakeholders in the BIM processes reduces the conflict areas and enhances the productivity and efficiency of the overall project. For example, the fact that the manufacturer was not included in the process created coordination issues, resulting in other sources of waste. The MEP SC stated: “[...] a lot of manufacturing errors, the fast-track approach was too much for him and he was not the best choice among the different manufacturers during the bidding phase due to the fixed-price bid to the lowest bidder." The MEP SC concluded that it would be better to go with manufacturers who work with BIM, even if it costs more, as that time loss is more expensive than paying more to a manufacturer.

\subsection{Potential success factors for BIM integration}

Thanks to the visualisation of information-processing problems that allowed the various maps to be compared, some emerging practices were discovered, easing the overall process and collaboration between the partners. Two success factors were highlighted by the study participants: the standardization of the processes within the BIM integration, and long-term relationships.

\subsubsection{The standardization of processes}

A BEP (BIM Execution Plan) is the document that drives the implementation of BIM on a project. Normally, one of the main goals of a BEP is to formalize how information is to be produced, to identify the roles and responsibilities in this production of information and, to describe the workflow for the production and exchange of information. The problem in traditional Design-Bid-Build contracts is that the GC and SC are not involved in the production of the BEP.

Since the PPP procurement approach requires an integrated team of design professionals and builders, it was possible for the GC to propose an overall information management strategy. The GC had a seasoned BIM team managing the project. The strategy, tools and processes used to produce, and exchange information were detailed in a BEP produced by the GC, who was also responsible for the BIM implementation for the project. This plan also identified the uses of BIM, based on the Penn State use taxonomy (Messner et al. 2010), and provided a detailed representation of the BIM processes throughout the building's life cycle.

The BEP presented a framework to produce a coordinated 3D model, which included the production of the information required by the client CMMS systems for the operation and management of the building. This rigorous $3 \mathrm{D}$ coordination process was designed to manage the detection and elimination of conflicts. Furthermore, the general contractor was already using BIM in other projects and was convinced of the advantages that BIM could bring to the realization of this project. Two platforms were deployed to manage the coordination process as well as the conflicts and deficiencies that occurred during the project. Aconex was used for managing monthly meetings and deficiencies, as it is a collaborative platform. Aconex provides a solution for BIM management, quality and safety, incorporating Request For Information (RFI), etc., with a centralization of the documents produced by all parties involved in a project. BIM 360 Glue was utilized to resolve conflicts and to manage weekly meetings, as it forces the implication of all parties involved in the entire process. This software demonstrates the value of having an integrated formula with a BIM-competent GC.

At first, the stakeholders were confused and reluctant to adhere to the BEP and found the BIM coordination meetings to be time consuming. However, over time, the meetings became more effective, and their relevance was recognized by the project team. Figure 4 shows a simplified version of an iteration of the 3D coordination of the models described in the BEP. The $3 \mathrm{D}$ coordination process required that the MEP SC receive the models from the architect and the engineers before coordinating the models and starting his work. Once the MEP SC completed the coordination of the models, having used them to detect any conflicts, they were sent back to the respective professionals with all the information necessary for them to continue their work. This model coordination process was carried out on a weekly basis to avoid major problems. Figure 5 shows the map realized by the GC concerning the $3 \mathrm{D}$ coordination process. 


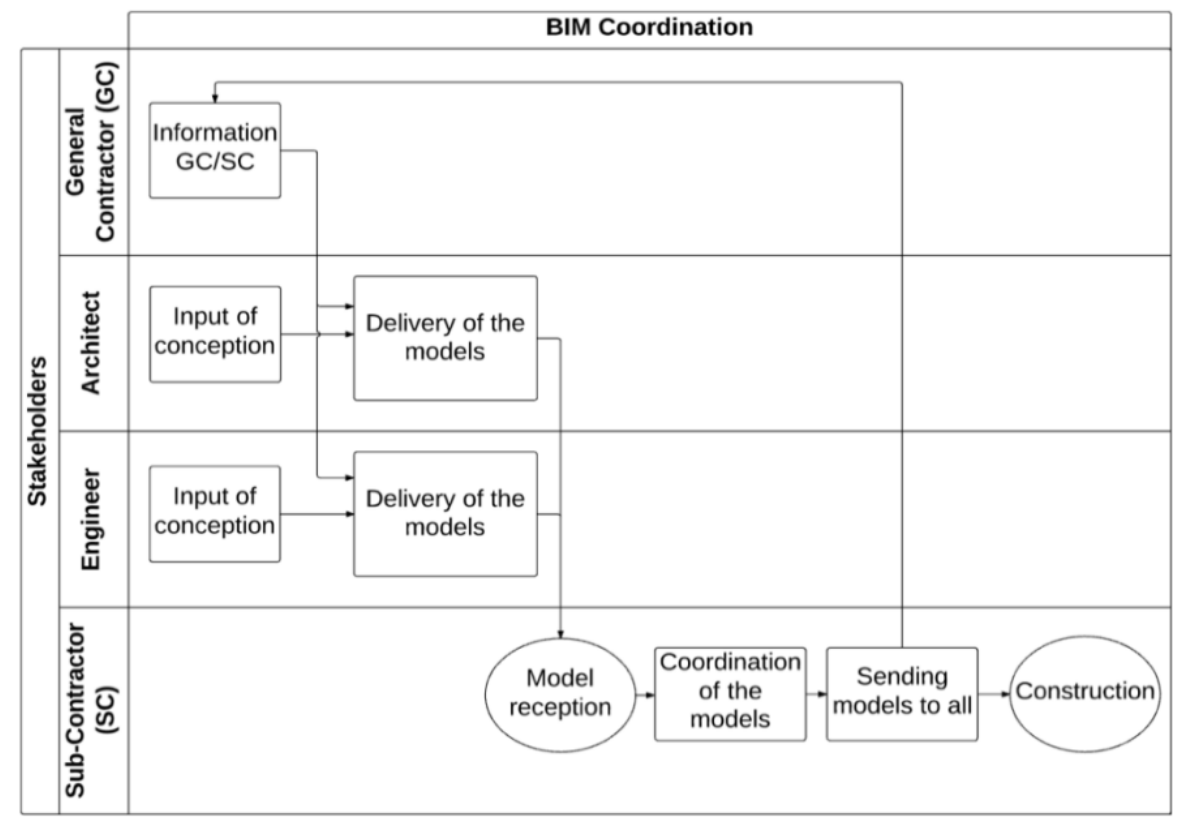

Figure 4. Basic iteration of the 3D coordination of the models between the actors

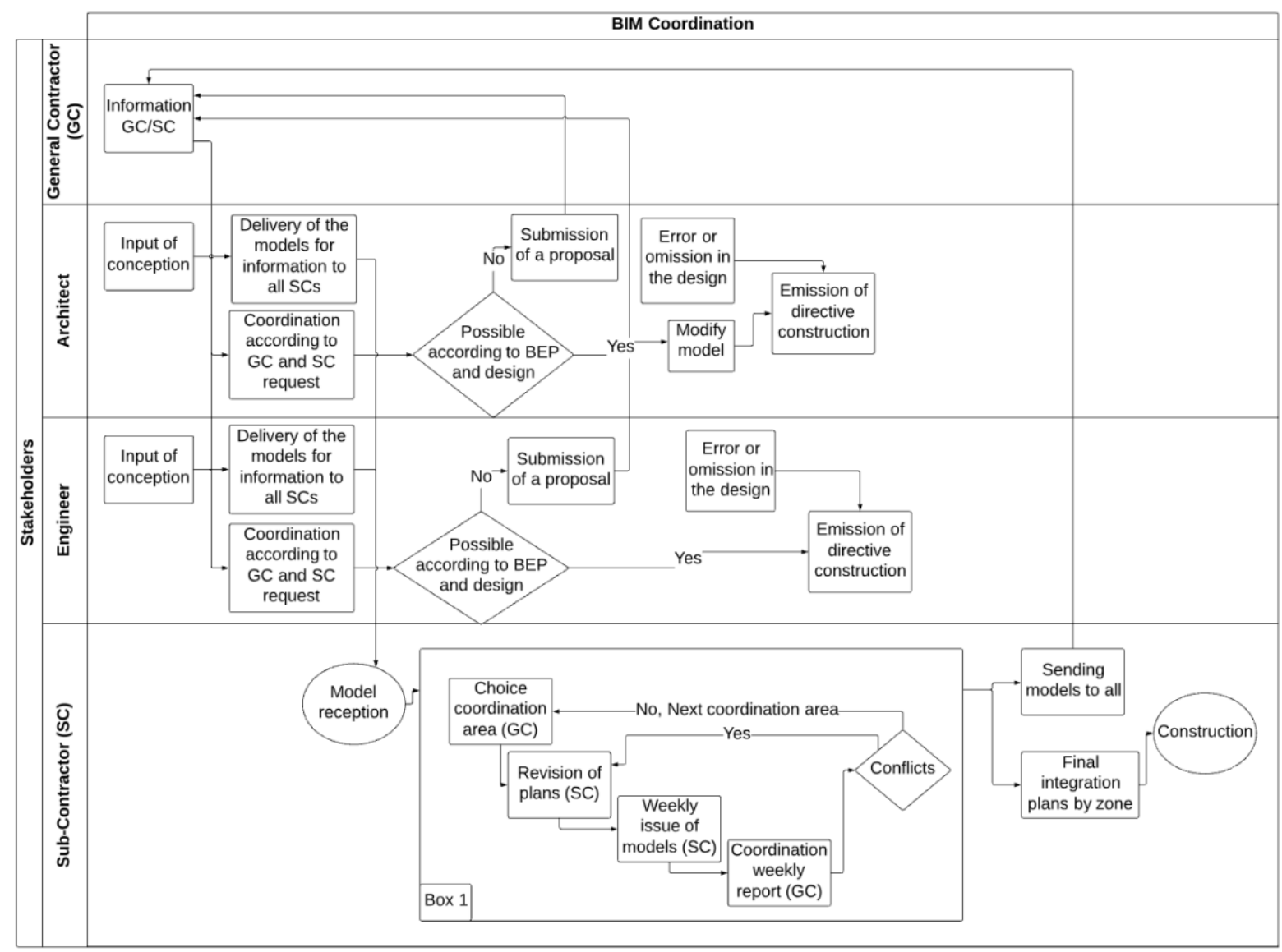

Figure 5. 3D coordination process from the GC's point of view

The 3D coordination process demonstrates the success of the GC in making all the project stakeholders aware of the overall information processing related to the project's progress. Once the various models of the professionals' designs were received, the coordination process was realized by the SC. The $3 \mathrm{D}$ coordination of the models was 
based on various sections of the model. When a section was complete, the SC coordinated its information and the process was repeated for each subsequent section (Figure 5, Box 1). The 3D coordination was done for specific areas defined by the GC and revised by the MEP SC. During the interviews, the actors admitted to having avoided many on-site errors thanks to this 3D coordination. The MEP SC also stated: "I can no longer imagine doing a project of this magnitude without the tools I have learned to use [BIM 360 Glue, Field, Revit, etc.] and the resulting collaborative methods." This statement clearly demonstrates the positive impact of collaboration on a construction project.

\subsubsection{Long term relationships}

Another advantage of using a procurement mode that favours an integrated supply chain is the possibility for the GC to select firms based not only on cost but also on their experience and performance based on previous relationships. As Egan (1998) suggested, "the industry must replace competitive tendering with long-term relationships based on clear measurement of performance and sustained improvements in quality and efficiency." Having worked successfully with these firms in other projects, the GC had developed long-term relationships, with a better understanding of each other's work patterns and ways of managing information using BIM. With the GC's deep knowledge of BIM, he was able to address the Push issues in information processing for the BIM 3D coordination process. For instance, the interviews were conducted when the project studied in this research had been completed and a second project had started with the same project team. With a better understanding of mapping workflows and information flows in the GC's BEP, the interviewees noticed a great improvement in how they managed their production and use of BIM models. Thus, it is possible to assume that visualization and trust relationships and the transition to new BIM methods improved and facilitated the relations in the second project. Moreover, the auto-confrontation exercise enabled them to better understand their own general process in addition to understanding the problem areas. By drawing the maps, they realized that the problems identified in the first project were no longer occurring in the new project. In this case, the transition to new practices was remarkably fast. However, the process was slowed down due to new stakeholders entering the process and/or not participating. The assumption is that the methods, once acquired, made it possible to improve the quality, efficiency and performance, and especially the management at the on-site level, which is the objective of the GC.

\section{DISCUSSION}

This discussion focusses on the identification of sources of waste in the information flows of a BIM construction project. For each source of waste identified in this research, potential solutions are proposed to provide a way to increase BIM benefits in future construction projects.

An overview of the identified sources of waste is given in Table 3, together with their cause(s) and the level of impact they can have in a construction project and the proposed potential waste reduction strategies to reduce waste in future construction projects.

Seven causes of waste were identified during the case study. These causes are regrouped into four sources of waste, as shown in Table 3. The four sources of waste discussed in this research are from the literature and are derived from the seven sources of waste identified by Ohno (1988) for workflows and material flows. The causes of waste come from the analysis of the results that can be categorized into the sources of waste. First, in a document-centric approach, the information, which is prescriptive in nature, is pushed, whereas the basis of an information-centric approach is to know the information needs of the next actor in the process in order to satisfy them. Not knowing those needs has a double impact: overproduction by not knowing the nature of the information required and thus working with incomplete information, which then leads to corrective actions and rework. Second, the semantic gap can also be linked to the overproduction of information, as well as to the need for rework. Differences in semantics leads to misunderstandings between the stakeholders, which in turn leads to mistakes in the generation of information or in work errors. Third, the decentralization between the design phase and the construction phase results in several sources of waste, such as the overproduction of information, rework and information transfer. The analysis showed that while the flow between traditional partners in the design phase was good, conflicts appeared in the construction phase because the roles and responsibilities were not clear. In addition, the exchange of information was not standardized between the engineers and the SCs. Fourth, speciality lenses lead to knowledge gaps because actors focus exclusively on their own speciality to realize their work as quickly as possible, neglecting other specialities. The stakeholders can understand and explain their own processes but cannot do the same with other stakeholders' processes, even when they are part of the same project. This situation leads to the overproduction of information and to the need for rework. Fifth, various software products were used during the project and several models were created. The use of numerous models led to coordination problems due to the 
loss of data when transferring information from one software platform to another, or when stakeholders were using and updating their own models in parallel without synchronizing them, creating coordination problems. Interoperability gaps lead to the overproduction of information, rework and problems in the transmission of information. Sixth, the transition from traditional to BIM practices requires major changes. Taylor and Bernstein (2009) treated the subject of changing the paradigm trajectories and noticed how stakeholders had difficulty understanding how the technology could affect their practices. Stakeholders are accustomed to their traditional practices and it takes both time and effort to adapt to a new practice. Finally, the lack of a common vision was observed between stakeholders, a lack that was partly responsible for some of the problems observed in collaboration and communication, contributing to the overproduction of information and to problems in information transmission.

Table 3. The identified sources of waste, their causes, impact and proposed potential solutions.

\begin{tabular}{|c|c|c|c|}
\hline Source of waste & Cause & Level of impact & $\begin{array}{l}\text { Proposed potential waste } \\
\text { reduction strategy }\end{array}$ \\
\hline \multirow{8}{*}{$\begin{array}{l}\text { Overproduction of } \\
\text { information }\end{array}$} & \multirow{5}{*}{$\begin{array}{l}\text { Lack of understanding of } \\
\text { information inputs needs } \\
\text { Semantic gaps } \\
\text { Decentralization between the } \\
\text { design and construction phase }\end{array}$} & Time loss & \multirow{2}{*}{$\begin{array}{l}\text { Standardization of } \\
\text { processes }\end{array}$} \\
\hline & & \multirow{2}{*}{$\begin{array}{l}\text { Non-value-added } \\
\text { information }\end{array}$} & \\
\hline & & & \multirow{2}{*}{$\begin{array}{l}\text { Collaboration \& } \\
\text { Communication }\end{array}$} \\
\hline & & Money loss & \\
\hline & & \multirow{4}{*}{$\begin{array}{l}\text { Creation of tension } \\
\text { between stakeholders }\end{array}$} & BIM execution Plan \\
\hline & Speciality lenses & & Pull approach \\
\hline & Interoperability gaps & & \\
\hline & Lack of common vision & & \\
\hline \multirow[t]{6}{*}{ Rework } & \multirow{6}{*}{$\begin{array}{l}\text { Semantic gaps } \\
\text { Decentralization between the } \\
\text { design and construction phase } \\
\text { Speciality lenses } \\
\text { Interoperability gaps }\end{array}$} & \multirow{6}{*}{$\begin{array}{l}\text { Time loss } \\
\text { Non-value-added activity } \\
\text { Money loss } \\
\text { Creation of tension } \\
\text { between stakeholders }\end{array}$} & \multirow{6}{*}{$\begin{array}{l}\text { Standardization of } \\
\text { processes } \\
\text { Collaboration \& } \\
\text { Communication } \\
\text { Formation } \\
\text { Pull approach }\end{array}$} \\
\hline & & & \\
\hline & & & \\
\hline & & & \\
\hline & & & \\
\hline & & & \\
\hline \multirow{5}{*}{$\begin{array}{l}\text { Transfer of } \\
\text { information }\end{array}$} & \multirow{5}{*}{$\begin{array}{l}\text { Decentralization between the } \\
\text { design and construction phase } \\
\text { Interoperability gaps } \\
\text { Lack of common vision }\end{array}$} & Time loss & \multirow{5}{*}{$\begin{array}{l}\text { Standardization of } \\
\text { processes } \\
\text { Collaboration \& } \\
\text { Communication } \\
\text { BIM execution plan }\end{array}$} \\
\hline & & Money loss & \\
\hline & & \multirow{3}{*}{$\begin{array}{l}\text { Creation of tension } \\
\text { between stakeholders }\end{array}$} & \\
\hline & & & \\
\hline & & & \\
\hline \multirow{4}{*}{$\begin{array}{l}\text { Difficulties in } \\
\text { understanding how } \\
\text { the technology } \\
\text { could affect } \\
\text { practices }\end{array}$} & \multirow[t]{4}{*}{ Organization of work issues } & \multirow{2}{*}{$\begin{array}{l}\text { Time loss } \\
\text { Non-value-added activity }\end{array}$} & Standardization of \\
\hline & & & processes \\
\hline & & \multirow[t]{2}{*}{ Money loss } & $\begin{array}{l}\text { Collaboration \& } \\
\text { Communication }\end{array}$ \\
\hline & & & Training \\
\hline
\end{tabular}

Depending on the source, several solutions are proposed to address the waste issues identified in this study. It has been demonstrated that increasing standardization helps to decrease waste (Koskela 2000). In this context, the standardization must be oriented towards the processes. Indeed, the standardization of activities and information should decrease waste three ways: first, by helping to close the semantic gap with a standardized vocabulary for all the stakeholders; second, by helping to reduce the decentralization of information between the design and the construction phases with standardized information transfer procedures between the stakeholders in each phase of a construction project; and third, minimizing the lack of knowledge with a better visualization and understanding 
of their own process as well as of the processes of the other stakeholders. During this study, with the help of the BEP, there was an attempt to standardize the transfer of information, with positive outcomes. However, even with positive results, this could not prevent the presence of waste in the information flows.

An approach from Lean production, the pull approach, could be implemented to reduce the overproduction of information and need for rework. As mentioned in the literature review, the pull approach allows stakeholders to produce their information according to the needs of the other actors, thus limiting the amount of information in the process. With the BIM approach, there is supposed to be an improvement in the collaboration and communication among the parties involved in construction projects (Liu, Van Nederveen, and Hertogh 2017). Indeed, with the centralization of production and exchange of information, the BIM approach will compel stakeholders to change their traditional work methods into a new method of team collaboration and communication (Gray et al. 2013). For example, to address the standardization of processes for the transfer of information, the BEP will cover the collaboration and communication among the stakeholders from the design phase to the end of the project to limit the interoperability gaps and speciality lenses, thereby reducing the appearance of tension between stakeholders. Finally, training makes it easier to understand the new technology. Indeed, when transitioning from a traditional to a BIM approach, changes are made in the processes. This training and experience will help stakeholders understand and use the new processes.

The use of VSM in this case was key to visualizing and to identifying sources of waste with the generation of current state maps of the various processes utilized in the project. Developed by Lean production, the VSM tool is used to improve the workflows. It has also revealed its potential to be used to improve information flows (Long et al. 2016). The aim of VSM is to identify and reduce sources of waste in the processes. The aim of the research was to provide potential solutions to the recurring problems identified in this study. The proposed solution would be to create a framework combining the various propositions listed above to reduce waste in BIM information flows. For future projects, the use of VSM could help reduce waste with the generation of future state maps to consider and remove all the identified problems and sources of waste.

\section{CONCLUSION}

BIM was introduced in the construction industry as a way to decrease fragmentation and inefficiency in project lifecycles by proposing a shared platform to centralize the production and exchange of information. A key finding in this research is that the project stakeholders must adapt the way they are handling information in order to leverage the benefits of BIM technology. Even when using new tools, the old way is still a major source of waste. While extensive research has been conducted regarding waste reduction in workflow and material flow, little has been done regarding the identification of problems in information flows or in identifying possible solutions, the main contribution of this paper. Another contribution is the demonstration of the value of adapting VSM for construction to visualize, identify and eliminate sources of waste in the information flow process. The study of information flows made it possible to demonstrate the presence of problems and successes in BIM processes.

This exploratory research focused on identifying conflicting and successful areas in the BIM processes between construction actors using an empirical approach. It also highlighted contradictions and issues in the BIM information processing and provided waste reduction strategies:

- Construction project stakeholders had difficulties moving from a document-centric to an information-centric approach, repeating traditional patterns of pushing information related to their specialty, leading to the overproduction of non-value information and to more rework;

- Collaboration was not optimum between the actors of a same process even with the use of BIM. It was demonstrated that there was a need to improve information processing between the different actors to reduce information waste; and

- Waste reduction strategies were proposed following the results analysis. These strategies aim to reduce the sources of waste identified for future projects.

Some of the limitations of this study are that only one project has been studied, limiting the amount of data used to develop and provide the solutions. One of the major problems in research in construction engineering is that all projects are different, making it difficult to generalize. For example, the maturity level with the use of BIM varies between project stakeholders, in this case, especially in the construction phase. This could accentuate the issues observed. However, a first taxonomy of waste for BIM information flow was based on this research. 
While this exploratory study has contributed to generating knowledge about the deployment of BIM, this project is part of a larger research effort aiming to improve information processing with BIM. This research shows the need to develop or adapt tools like VSM to better identify sources of waste in the production and exchange of information as a next step. With a better definition of the sources of waste in the information flows, more solutions can be proposed and tested in the future.

\section{REFERENCES}

Aapaoja, A., and Haapasalo, H. (2014). "The Challenges of Standardization of Products and Processes in Construction." In 22nd Annual Conference of the International Group for Lean Construction, edited by B. T. Kalsaas, Koskela, L. \& Saurin, T. A., pp. 983-93. Oslo, Norway.

Ahankoob, A., S.M. Khoshnava, R. Rostami, and Preece C. (2012). "BIM perspectives on construction waste reduction " In Management in Construction Research Association (MiCRA) Postgraduate Conference, pp. 195-99. Malaysia.

Cetin, M., and G. F. List. (2002). "Integrating Information Flow and Physical Flow in Transportation." In Seventh International Conference on Applications of Advanced Technologies in Transportation, edited by ASCE, pp. 951-58. Boston Marriot, Cambirdge, Massachusetts, United States.

Clot, Yves, Daniel Faïta, Gabriel Fernandez, and Livia Scheller. (2000). 'Entretiens en autoconfrontation croisée : une méthode en clinique de l'activité', Perspectives interdisciplinaires sur le travail et la santé, Accessed 25th January 2017. http://pistes.revues.org/3833.

Coates, P., Y. Arayici, L. Koskela, M. Kagioglou, C. Usher, and K O'Reilly. (2010). "The limitations of BIM in the architectural process." In First International Conference on Sustainable Urbanization.

Crotty, Ray. (2013). The impact of building information modelling: transforming construction (Routledge).

Deutsch, Randy. (2011). BIM and integrated design: strategies for architectural practice (John Wiley \& Sons).

Dossick, Carrie Sturts, and Gina Neff (2011). 'Messy talk and clean technology: communication, problem-solving and collaboration using Building Information Modelling', Engineering Project Organization Journal, 1: pp. 83-93.

Eadie, R., H. Odeyinka, M. Browne, C. McKeown, and M. Yohanis. (2014). 'Building Information Modelling Adoption: An Analysis of the Barriers to Implementation', Journal of Engineering and Architecture, 2: pp. 77-101.

Eastman, C.M., C. Eastman, P. Teicholz, R. Sacks, and K. Liston. (2011). BIM handbook: A guide to building information modeling for owners, managers, designers, engineers and contractors (John Wiley \& Sons).

Egan, John. (1998). Rethinking Construction, construction task force report for department of the environment, transport and the regions (HMSO, London).

Fellows, R. F., and A. M. Liu (2015). Research methods for construction (John Wiley \& Sons).

Forgues, E. C., V. Carignan, D. Forgues, and S. B. Rajeb (2016). "A framework for improving collaboration patterns in BIM projects." In International Conference on Cooperative Design, Visualization and Engineering, edited by Springer International Publishing.

Franz, Bryan, Robert Leicht, Keith Molenaar, and John Messner (2016). 'Impact of Team Integration and Group Cohesion on Project Delivery Performance', Journal of Construction Engineering and Management, 143 : p. 04016088.

Garcia Lopez, Nelly (2017). 'An activity and flow-based construction model for managing on-site work', Stanford University.

Garcia Lopez, Nelly, and Martin Fischer (2016). "A construction workflow model for analyzing the impact of inproject variability." In Construction Research Congress 2016, edited by ASCE. San Juan, Puerto Rico.

Goedert, James D., and Pavan Meadati (2008). 'Integrating Construction Process Documentation into Building Information Modeling', Journal of Construction Engineering and Management, 134: pp. 509-16. 
Gray, Matthew, Jason Gray, Melissa Teo, Seokho Chi, and Yan Ki Fiona Cheung (2013). "Building information modelling: an international survey." In World Building Congress 2013. Brisbane, Australia, 5-9 May 2013.

Hammer, Michael, and James Champy (1993). Reengineering the corporation (HarperBusiness).

Hancock, D. R., and B. Algozzine (2016). Doing a case study research: A practical guide for beginning researchers (Teachers College Press).

Innes, S. (2004). "Developing tools for designing out waste pre-site and on-site." In Proceedings of Minimising Construction Waste Conference: Developing Resource Efficiency and Waste Minimisation in Design and Construction, edited by New Civil Engineer. London, UK.

Kassem, M., and B. Succar (2017). 'Macro BIM adaption: Comparative Market Analysis', Automation in construction, 81: pp. 286-99.

Kiviniemi, Arto (2011). 'The effects of integrated BIM in processes and business models.' in, Distributed intelligence in design (Wiley Blackwell: Chichester, UK).

Koskela, L. (2000). 'An exploration towards a production theory and its application to construction', Helsinki University of Technology.

Liu, Yan, Sander Van Nederveen, and Marcel Hertogh (2017). 'Understanding effects of BIM on collaborative design and construction: An empirical study in China', International Journal of Project Management, 35 : pp. 686-98.

Long, S., E.H. Ng, C. Downing, and B. Nepal (2016). "Value Stream Map as an Initiator of a Continuous Improvement Process: a Case Study." In Proceedings of the American Society for Engineering Management 2016 International Annual Conference, edited by American Society for Engineering Management (ASEM), pp. 1-6.

Martinez, Eder H., Ariana M. Alvear, Iris D. Tommelein, and Glenn Ballard (2015). "Formwork standardization and production flow: Lessons from an affordable housing project in Ecuador." In 23rd Annual Conference of the International Group for Lean Construction, edited by O. Seppänen, González, V. A. \& Arroyo, P., pp. 53-62. Perth, Australia, 29-31 Jul 2015.

Messner, John, Chimay Anumba, Craig Dubler, S. Goddman, C. Kasprzak, R. Kreider, R. Leicht, C. Saluja, and N. Zikic (2010). BIM Project Execution Planning Guide version 2.0 (The Computer Integrated Construction Research Program (CIC), Penn State University).

Miettinen, Reijo, and Sami Paavola (2014). 'Beyond the BIM utopia: Approaches to the development and implementation of building information modeling', Automation in construction, 43: pp. 84-91.

Mirarchi, Claudio, Daniela Pasini, Alberto Pavan, and Bruno Daniotti (2017). "Automated IFC-Based Processes in the construction sector: A Method for Improving the information Flow." In LC3 2017: Volume I Proceedings of the Joint Conference on Computing in Construction (JC3), pp. 491-98. Heraklion, Greece.

Moore, David R., and Andrew R. J. Dainty (2001). 'Intra-team boundaries as inhibitors of performance improvement in UK design and build projects: a call for change', Construction Management and Economics, 19: pp. 559-62.

Ohno, T. (1988). Toyota Production System: beyond large-scale production (Productivity Press: New York, USA).

Osmani, M., A. D. F. Price, and J. Glass (2005). 'Potential for construction waste minimisation through design', WIT Transactions on Ecology and the Environment, 84: pp. 575-84.

Otjacques, B., P. Post, and F. Feltz (2003). "Management of information flows during construction projects." In.: CIB REPORT.

Porwal, Atul (2013). 'Construction waste management at source: A Building Information Modeling based system dynamics approach', University of British Columbia.

Scherer, Raimar, and Ali Ismail (2011). "Process-based simulation library for construction project planning." In Proceedings of the Winter Simulation Conference, edited by IEEE, pp. 3493 - 504. Phoenix, AZ, USA. 
Smits, Wim, Marc van Buiten, and Timo Hartmann (2017). 'Yield-to-BIM: impacts of BIM maturity on project performance', Building Research \& Information, 45: pp. 336-46.

Taylor, John E., and Phillip G. Bernstein (2009). 'Paradigm Trajectories of Building Information Modeling Practice in Project Networks', Journal of Management in Engineering, 25: pp. 69-76.

Tribelsky, Effi, and Rafael Sacks (2010). "The relationship between information flow and project success in multidisciplinary civil engineering design." In 18th Annual Conference of the International Group for Lean Construction, edited by K. \& Alves Walsh, T. Haifa, Israel, 14-16 Jul 2010.

Turk, Ziga (2000). 'Construction IT: Definition, Framework and Research Issues', Faculty of Civil and Geodetic Engineering on the doorstep of the millennium : on the occasion of its 80th anniversary: pp. 17-32.

Volk, Rebekka, Julian Stengel, and Frank Schultmann (2014). 'Building Information Modeling (BIM) for existing building - Literature review and future needs', Automation in construction, 38: pp. 109-27.

Wang, K., Y. Guan, D. Jiang, and P. Yao (2010). "Analysis of information flow control in military supply chain management." In Supply Chain Management and Information Systems (SCMIS), 2010 8th International Conference, pp. 1-4. IEEE.

Wang, Li, and Fernanda Leiti (2016). 'Formalized knowledge representation for spatial conflict coordination of mechanical, electrical and plumbing (MEP) systems in new building projects', Automation in construction, 64: pp (20-26.

Winch, Graham M. (2009). Managing construction projects (John Wiley \& Sons).

Yin, Robert K. (1994). Case Study Research. Design and Methods (Second edition. Thousand Oaks: Sage).

Yu, H., T. Tweed, M. Al-Hussein, and R. Nasseri (2009). 'Development of Lean Model for House Construction Using Value Stream Mapping', Journal of Construction Engineering and Management, 135: pp. 782-90.

Zadeh, Puyan A., Sheryl Staub-French, and Rachel Pottinger (2015). "Review of BIM quality assessment approaches for facility management." In ICSC15: The Canadian Society for Civil Engineering 5th International/11th Construction Specialty Conference. University of British Columbia, Vancouver, Canada.

Zhang, R., A. M. M. Liu, and I. Y. S. Chan (2018). 'Effects of Quality and Quantity of Information Processing on Design Coordination Performance', World Journal of Engineering and Technology, 6: pp. 41-49. 